\title{
CHAPTER 93
}

SOME CONSIDERATIONS ON HYDRAULIC DESIGN OF BOTTOM WATER INTAKE

Shin-1chi Senshu

Supervisor, Coastal Hydraulic Division, Hydraulics Department, Technical Laboratory, Central Research Institute of Electric Power Industry, Tokyo, Japan

\section{ABSTRACT}

The selective withdrawal characteristics of bottom water intake placed on the sea bed for the condenser cooling system of steam power station are presented and several design methods are proposed The results of field observations are also shown.

\section{INTRODUCTION}

Recently in Japan, the most intake structures for condenser cooling system of thermal (or nuclear) power stations sited on a seashore are designed as bottom water intake in order to withdraw a Iarge quantity of clean water of low temperature from the deep layer of thermally stratified sea basin. The following types have been used for such intake structures: (a) skimmer-wall type, (b) horızontal inlet of intake pipe, and (c) vertical inlet of intake pipe. (shown in Fig. 1) The characteristics of skimmer-wall type intake were previously studied by the author and the bottom water intake of this type has been constructed at several nower stations

In this paper, the characteristics of horizontal type inlet of bottom water intake pipe are presented on the basis of fundamental experiments conducted at the Hydraulics Laboratory of CRIEPI and some design methods are proposed. The results of field observations are also shown which were carried out to examine the effect of bottom water withdrawal by such structures

\section{CHARACTERISTICS OF HORIZONTAL TYPE INLET}

The withdrawal characteristics of horizontal type inlet depend on the following values; (see Fig. I (b))

$b$ width of rectangular opening of inlet,

$h_{o}$ height of opening,

$\Delta \cdot$ depth from interface of stratification to top of opening,

$z_{0}$ rıse from sea bed to bottom of opening,

$L$ t topographical clearance behind opening (horizontal distance from opening to bank),

$L^{\prime}$ length of visor horizontally projecting at the top of opening,

$\rho$ density of lower layer water,

A $\rho$ difference in density of two layers water,

$Q_{c}$ maximum discharge under critical condition, which can be taken from the lower layer water wi thout drawdown of interface,

$u_{o}$ mean velocity at the opening under critical condition, $u_{o}=Q_{c} / b h^{\circ}$

Considering the effect of three-dimensional flow approaching the inlet, the critical withdrawal condition for the horizontal type inlet with rectangular opening can be obtaned from the energy equation as follows 


$$
F_{z_{0}}=c\left(\Delta h / h_{0}\right)^{3 / 2} \quad \ldots \quad \ldots \ldots \ldots
$$

where

$$
F_{\imath_{0}}=\frac{u_{0}}{\sqrt{g(\Delta \rho / \rho) h_{0}}}
$$

In Eq. 1, c denotes the coefficient depending on the velocity distribution of approaching flow and should be determined experimentally as the function $l=L / h o$, $m=z_{0} / h_{0}, n=b / h_{0}$ and $l^{\prime}=L^{\prime} / h_{0}$

The value of $c$ is shown in Fig. 2 (a) and (b), which is obtalned from the these figures correspond to the opening of rectangular section whose ratio of width to height is $4 \cdot 1(n=4)$ However, the results of the experiment show that the effect of the opening geometry (ratio of widt to height, $n$ ) on the withdrawal characteristics is not dominant for the $r$ range of $n=2 \sim 4$. For the conslderably larger value of $n$, the value of c has a tendency to become smalier, since the effect of the three-dimensional inflow from the both sides of the opening declines and the two-dimensional inflow preval It ls found from Fig. 2 (b) that the visor installed at the top of the condition.

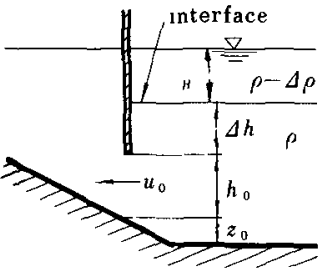

(a)

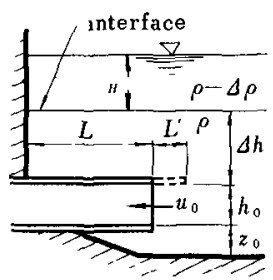

(b)

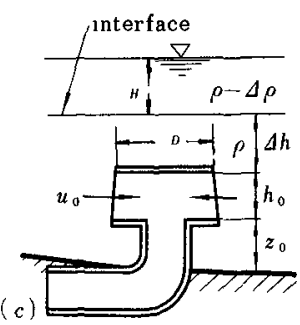

VERTICAL TYPE INLET

SKIMMER WALL TYPE

HORIZONTAL TYPE INLET

Fig. 1 Type of bottom water intake

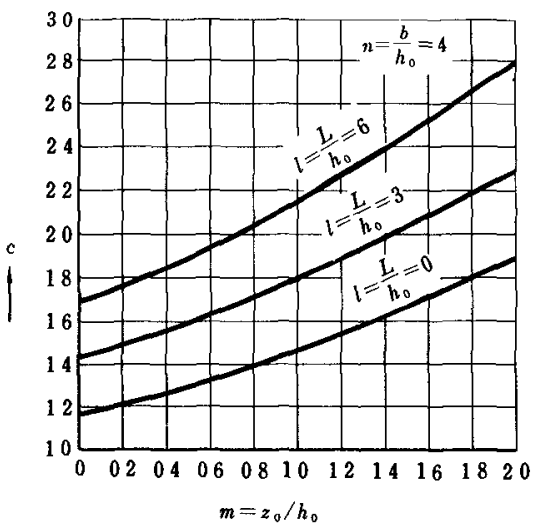

(a)

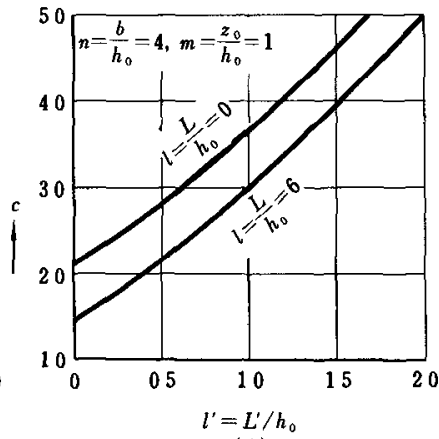

(b)

Fig 2. Value of coefficient, c, in Eq. 1. 


\section{HYDRAULIC DESIGN OF BOTTOM WATER INTAKE}

1. Method of economical design to minimize the total depth

This method Is based on the idea that the most economical size of the intake ls glven by the opening helght $h_{o}$ so as to minimize the total depth below the interface, $z_{0}+h_{0}+\Delta h$, for a given discharge under the critical condltion. The economical opening height $h_{0}$ in this manner is obtained from Eq 1 for horizontal type inlet, by differentiating $z_{0}+h_{0}+\Delta h$ with respect to $h_{0}$ and equating to zero, that is

$$
h_{0}=\left\{\frac{2}{3(1+\pi)}\right\}^{2 / 5}\left(\frac{Q}{n c \sqrt{g \frac{\Delta \rho}{\rho}}}\right)^{2 / 5} \quad \ldots . .
$$

and the corresponding depth $\Delta h$ Is

$$
\Delta h=\left(\frac{Q}{n_{0} \sqrt{g \frac{\Delta \rho}{\rho}}}\right)^{2 / 3} \frac{1}{h_{0}^{2} / 3} \quad \ldots \ldots \ldots \ldots
$$

The economical opening helght, $h_{o}$, for skimmer-wall type intake can be obtained in the same manner from the critical withdrawal condition, $F_{0}=0.9(A h / h n)$, based on the result of the two-dimenstional experiment presented in the author's previous study, as follows.

$$
h_{0}=\left(\frac{q}{2 \times 09 \sqrt{g \frac{d \rho}{\rho}}}\right)^{2 / 3} \quad \ldots \ldots, \ldots, \ldots \ldots
$$

and the corresponding depth $\Delta h \quad$ is

$$
\Delta h==\frac{q}{0.9 \sqrt{g \frac{\Delta \rho}{\rho} h_{0}}} \quad, \quad \ldots \ldots \ldots
$$

where, $q$ ls maximum discharge per unit width of sklmmer-wall under the critıcal condition

Several examples of bottom water intake of horizontal type inlet designed by this method are shown in Table-1 in these examples, maximum intake discharge is $Q=11 \mathrm{~m}^{3} / \mathrm{sec}$, depth of upper layer $\mathrm{H}=4 \mathrm{~m}$, and relative density difference $\Delta \rho / \rho=0.0017$ (corresponding to temperature difference between upper and lower layer water, $\Delta T=5 \mathrm{o}^{\mathrm{C}}$ ).

Teble-l. Horizontal type anlet designed by the method to manimize total depth $(\mathrm{n}=4)$.

\begin{tabular}{|c|c|c|c|c|c|c|}
\hline No. & Design condition & $\begin{array}{c}\Delta h \\
(\mathrm{~m})\end{array}$ & $\begin{array}{c}h_{0} \\
(\mathrm{~m})\end{array}$ & $\begin{array}{c}z_{0} \\
(\mathrm{~m})\end{array}$ & $\begin{array}{c}\text { Total depth } \\
\boldsymbol{H}+\Delta h+h_{0}+z_{0} \\
(\mathrm{~m})\end{array}$ & $\begin{array}{c}u_{0} \\
(\mathrm{~m} / \mathrm{s})\end{array}$ \\
\hline 1 & $\iota=6, \mathrm{~m}=0, \quad l^{\prime}=0$ & 3.23 & 216 & 0 & 9.39 & 0.590 \\
2 & $l=6, \mathrm{~m}=1, l^{\prime}=0$ & 3.88 & 1.30 & 1.30 & 10.48 & 1.627 \\
3 & $\iota=6, \mathrm{~m}=1.5, l^{\prime}=0$ & 4.04 & 1.08 & 1.62 & 10.74 & 2.360 \\
4 & $\iota=6, \mathrm{~m}=0.5, l^{\prime}=1$ & 2.88 & 1.28 & 0.64 & 8.80 & 1.678 \\
\hline
\end{tabular}


2. Method of providing the inlet velocity so as to keep stability of the interface

The design method described above is apt to give rather large magnitude of inlet velocity, which promotes occurrence of turbulent mixing at the interface and results in simultaneous inflow from the upper layer. It would be the practical method, therefore, to determine the value of $h_{0}$ and $d h$ under the critical condition, by providing first the inlet velocity $u_{0}$ with the magnitude to keep stability of the interface.

For horizontal type inlet of rectangular opening $\left(b=n h_{0}\right)$,

$$
h_{0}=\sqrt{\frac{Q}{n u_{0}}} \quad \cdot \quad \ldots \ldots \cdot \quad \ldots \ldots \cdot, \cdot(6)
$$

and

$$
\Delta h=\left(\frac{u_{0} h_{0}}{c \sqrt{g \frac{d p}{p}}}\right)^{2 / 3} \quad \text {. } \quad \ldots . . .
$$

It is adequately recommended that the magnitude of $u_{o}$ should be taken as 0.10 $0.20 \mathrm{~m} / \mathrm{sec}$, on the basis of stability condition of interface of two-layer stratification.

Figure 3 is the design diagram of horizontal type inlet by this method based on Eqs. 6 and 7 for the condition $\Delta \rho / \rho=0.0017\left(\Delta T=5{ }^{\circ} \mathrm{C}\right), \mathrm{n}=4$, and $c=117$ $(l=0, \mathrm{~m}=0)$.

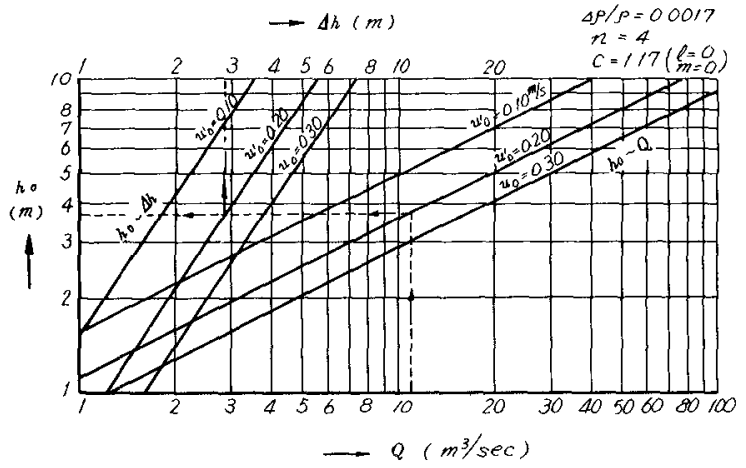

Fig. 3. Design diagram for horizontal type inlet by method of providing the inlet velocity.

For skimmer-wall type bottom water intake, the values of $h_{0}$ and corresponding $\Delta h$ for the given inlet velocity $u_{0}$ are determined by

$$
h_{0}=q / u_{0} \quad . \quad \ldots \ldots \ldots, \ldots, \ldots, \ldots(8)
$$

and 


$$
\Delta h=\left(\frac{u_{o}}{09 \sqrt{g \frac{d \rho}{\rho}}}\right) h_{o}^{\frac{1}{2}}
$$

Several examples of botton water intake of horizontal type inlet designed by this method are shown in Table-2 In these examples, the values of $Q, H$ and $A \rho / \rho$ are same as the ones for the above examples in Table-1

Table 2 Horizontal type and skimmer-wall type inlet designed by the method so as to keep stability of interface (inlet velocity, $u_{o}$, is given first).

\begin{tabular}{|c|c|c|c|c|c|c|c|}
\hline No & Design condition & $\begin{array}{c}\Delta h \\
(\mathrm{~m})\end{array}$ & $\begin{array}{c}h_{0} \\
(\mathrm{~m})\end{array}$ & $\begin{array}{c}z_{o} \\
(\mathrm{~m})\end{array}$ & $\begin{array}{c}\text { Total depth } \\
B+\Delta h+h_{0}+z_{0} \\
\text { (m) }\end{array}$ & $\begin{array}{c}b \\
(\mathrm{~m})\end{array}$ & $\begin{array}{l}\text { Given inlet } \\
\text { veloczty } u_{c} \\
(\mathrm{~m} / \mathrm{sec})\end{array}$ \\
\hline$a-1$ & $l=0, m=0, \quad l^{\prime}=\overrightarrow{0}$ & 288 & 3.70 & o & 1058 & 148 & 020 \\
\hline$a-2$ & $l=0, \mathrm{nl}=0 \quad l=0$ & 330 & 3.00 & 0 & 1030 & $\begin{array}{ll}12 & 0\end{array}$ & 030 \\
\hline$a-3$ & $\mathrm{n}=4, \quad l=6, \mathrm{~m}=1, \quad l^{\prime}=0$ & 192 & 370 & 370 & 1332 & 148 & 020 \\
\hline$a-4$ & $l=6, \mathrm{~m}=03, \vec{l}=0.4$ & 282 & 370 & 111 & 1063 & $\begin{array}{ll}14 & 8\end{array}$ & 020 \\
\hline$h$ & $\begin{array}{l}\text { Skimer-wall type inlet } \\
\text { (two-dimensional case of a-1) }\end{array}$ & 332 & 372 & 0 & 1104 & $\begin{array}{ll}14 & 8\end{array}$ & 020 \\
\hline
\end{tabular}

\section{Hydraulic design of vertical type inlet}

The vertical type inlet with cover plate and bottom guide plate as shown in Fig. 1 (c), can be designed in the same manner by applying the above-mentioned methods for the horizontal type inlet to each divided portion around the opening

Divide the cylindrical opening formed between the upper cover plate and the lower giude plate of diameter $D^{\prime}$ into $\alpha$ portions (for each divided portion, $n=$ $\left.\left(\pi D^{\prime} / 2\right) / h_{0}\right)$, and apply the design formular to each portion of $\beta$ among $\alpha$, assuming that the remaining part $(\alpha-\beta)$ is ineffectual for withdrawing water due to the surrounding obstruction.

For a given discharge $Q$ and inlet velocity $u_{0}$, the opening height $h_{0}$ is obtained from

$$
h_{o}=\sqrt{\frac{Q}{n \beta^{u o}}}
$$

then, the corresponding depth $\Delta h$ can be calculated by Eq. 7, in which the value of coefficient $c$ should be taken for the case of $l=0$.

On the other hand, in the economical design to minimize the total depth at the inlet, the calculating formulas are as follows: 


$$
\begin{aligned}
& D=\left\{\frac{2 n \alpha}{3 \pi(1+m)}\right\}^{3 / 5}\left(\frac{Q}{c \pi \frac{\beta}{\alpha} \sqrt{g \frac{d \rho}{\rho}}}\right)^{3 / 5} \\
& h_{0}=\frac{\pi D^{\prime}}{n \alpha} \quad . \quad . \quad \ldots \\
& u_{0}=\frac{Q}{\pi D^{\prime \prime \frac{\beta}{\alpha} h_{0}}}
\end{aligned}
$$

For a given discharge $Q$, the diameter of the cylindrical opening, $D^{\prime}$, is obtained from Eq 11, then successively ho from $\mathrm{Eq} 12$, wo from Eq 13 and $\Delta h$ from Eq. 7 .

Two design examples of bottom water intake of vertical type inlet for the same value of $Q$, II and $\Delta \rho / \rho$ as $\perp$ n examples above described, are shown in Table-3

Table-3. Vertical type inlet for the

given inlet velocity, $u_{0}=0.20 \mathrm{~m} / \mathrm{sec}$

\begin{tabular}{|c|c|c|c|c|c|c|c|}
\hline No & Design condition & $\begin{array}{c}\mathrm{D}^{\prime} \\
(\mathrm{m})\end{array}$ & $\begin{array}{c}\Delta h \\
(\mathrm{~m})\end{array}$ & $\begin{array}{c}h_{0} \\
(\mathrm{~m})\end{array}$ & $\begin{array}{c}z_{0} \\
(\mathrm{~m})\end{array}$ & $\begin{array}{c}\text { Total depth } \\
H+\Delta h^{2}+h_{0}+z_{0} \\
(\mathrm{~m})\end{array}$ \\
\hline $\mathrm{c}-1$ & $l=0, \mathrm{~m}=0.5, \quad \iota^{\prime}=0.4, \mathrm{n}=4, \alpha=4, \beta=3$, & 10.90 & 1.48 & 2.14 & 1.07 & 8.69 \\
$\mathrm{c}-2$ & $l=0, \mathrm{~m}=0$ & $3, \quad \iota^{\prime}=0.4, \mathrm{n}=2, \alpha=4, \beta=3$, & 7.72 & 1.90 & 3.03 & 0.91 & 9.85 \\
\hline
\end{tabular}
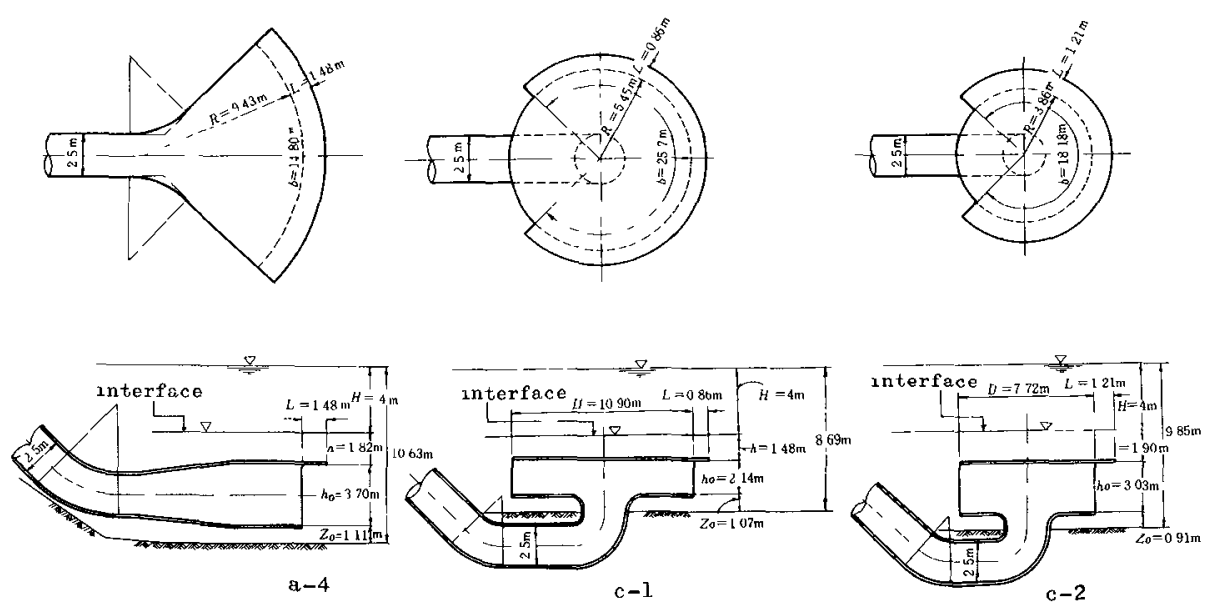

F1g. 4. Design examples of horlzontal type and vertical type bottom water intake. 
These two vertıcal type bottom water intakes are sketched in Fig. 4, together with one example of horizontal type intake (a-4 in Table-2) Comparing c-l with $c-2, c-2$ for $n=2$ is rather economical than $c-1$ for $n=4$, because the volume of the whole structure for the former $1 \mathrm{~s} 2 / 3$ of the one for the latter.

4 Method of permitting to entrain the surface layer water of high temperature beyond the critical condition

Above mentioned are the design methods to take the colder bottom water from the thermally stratified basin and to prevent the warmer surface water from withdrawing into the cooling system. However, when the flow rate increases and exceeds the maximum discharge under the critical condition, the interface is drawn down below the top of the opening and simultaneous inflow from the upner layer may develop.

To permit the entrainment of warmer water from the upper layer to some extent brings the design method to obtain more economical intake structures than designed under critical condition. In case of such a design method, the required depth $\Delta h$ for horizontal type inlet is estimated by the following equation for a given entrainment factor $\lambda$;

$$
\Delta h=\Delta h_{c}(1-\lambda)^{2 / 3}-\lambda h_{0} \quad \ldots \ldots \ldots \ldots
$$

in which, Sho is the depth for the critical design given by Eq 7 , and entrainment factor $\lambda$ is the ratio of inflow from the upper layer to total discharge withdrawn through the opening. Mean water temperature of cooling water, To, when warmer surface water is entrained, is estimated by

$$
T \circ=\lambda T_{1}+(1-\lambda) T_{2} \quad \cdot \quad, \quad \ldots \ldots \ldots \ldots, \ldots(1.5)
$$

where $T_{1}$ and $T_{2}$ is water temperature in upper and lower layer, respectively

For two-dimensional skimmer-wall type intake, the following relation should be used, instead of $\mathrm{Eq} 14$

$$
\Delta h=\Delta h c(1-\lambda)^{\frac{1}{2}}-\lambda h_{0} \quad \text {. . . . . . . }
$$

Equation 15 or $\mathrm{Eq} 16$ can also be used to estimate the entralnment factor $\lambda$ for the existing intake structures

F1ELD OBSERVATIONS

To examine the effect of bottom water intake structures designed by the author's method, field observations have been carried out at several thermal power stations

Figure 5 shows an example of the observed vertical distributions outside and inside of the skimmer-wall type bottom water intake at SAKAl-Ko Thermal Power Station sited in Osaka Bay The intake structure was completed in July of 1967. The maximum discharge of cooling water is $100 \mathrm{~m}^{3} / \mathrm{sec}$ for the output of $2000 \mathrm{MW}$ in its final project. The opening helght below the skimmer-wall, $h_{0}, 1 \mathrm{~s} 4.8 \mathrm{~m}$, and the designing mean velocity at the opening, uo, is $016 \mathrm{~m} / \mathrm{sec}$.

As seen in Fig. 5, the consplcuous stratification due to water temperature difference develops in the basin in front of the intake in August, and this bottom water intake 1 s of great advantage to withdraw colder clean water. The average temperature of cooling water measured at the pumping pit was $24{ }^{\circ} \mathrm{C}$ in spite of the water temperature of $30.5^{\circ} \mathrm{C}$ in surface layer outside of the skimmer-wall. 
water temperature $\left({ }^{\circ} \mathrm{C}\right)$

-water temperature $\left({ }^{\circ} \mathrm{C}\right) \rightarrow$ water temperature $\left({ }^{\circ} \mathrm{C}\right)$

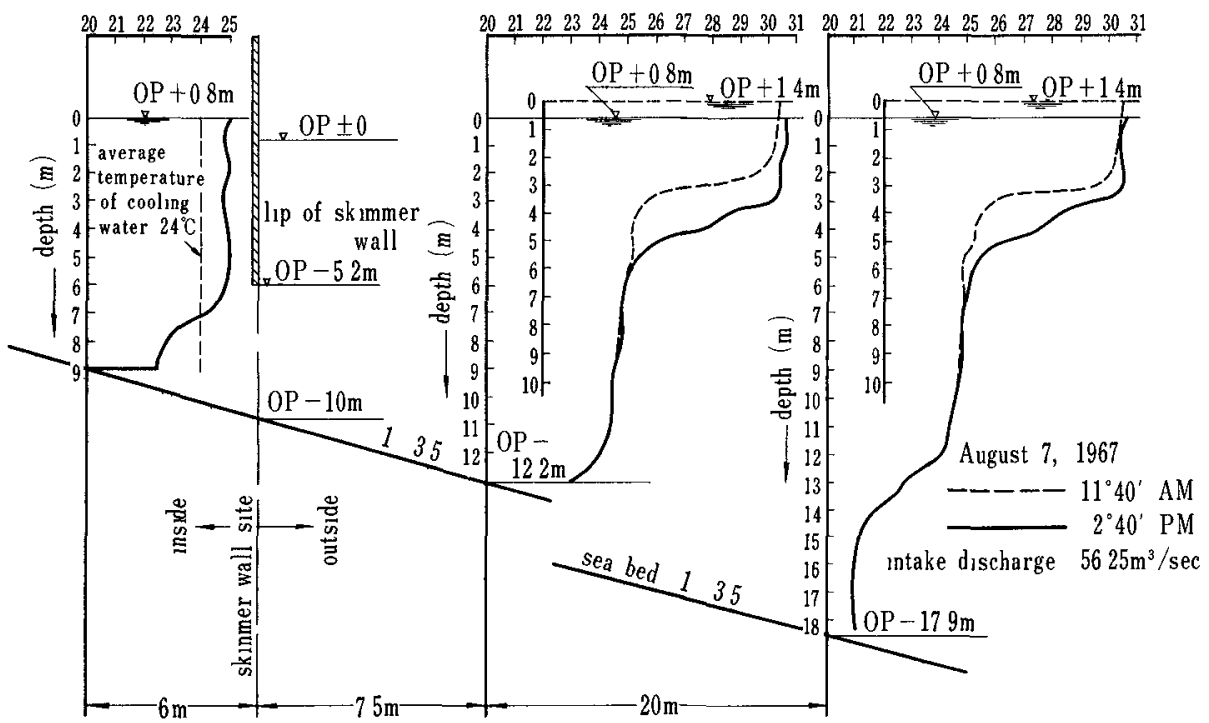

Fig. 5. observed water temperature distribution at bottom water intake of cooling system for Sakal-ko Thermal Power Station

Figure 6 shows another example of vertical temperature distributions outside of the skimmer-wall type bottom water intake observed at SHIN-SHIMIZU Thermal Power Station sited in Shimizu Port. The maximum discharge of cooling water is 11.7 $\mathrm{m}^{3} / \mathrm{sec}$ for the total output of $306 \mathrm{MW}, h_{0}=4.12 \mathrm{~m}$ and $u_{0} 1 \mathrm{~s} 0.07 \mathrm{~m} / \mathrm{sec}$.

The cooling water discharge during the testing period was $6.15 \mathrm{~m}^{3} / \mathrm{sec}$.

Assuming the discontinuous temperature distribution outside of the skimmerwall shown by dotted line in Fig. 6, the average temperature of cooling water 15 calculated by the author's method as $25.85{ }^{\circ} \mathrm{C}(\lambda=6 \%)$ in ebb tide and $26.1{ }^{\circ} \mathrm{C}$ $(\lambda=0)$ in flood tide. These values are in quite agreement with the observed water temperature at pumping pat.

Figure 7 shows the water temperature distribution in front of the horizontal type bottom water intake with visor observed at ICHIHARA Thermal Power Station in Tokyo Bay Assuming that $T_{1}=26.5{ }^{\circ} \mathrm{C}$ for upper layer, $T_{2}=215$ o $\mathrm{C}$ for 1 ower layer, depth of surface layer $\mathrm{H}=3.5 \mathrm{~m}$ from the observed temperature distribution on August 15, the average temperature of cooling water 1 s estimated as $21.7{ }^{\circ}(\lambda=4.5 \%)$.

Figure 8 shows the water temperature distribution around the vertical type inlet of bottom water intake pipe for SAKAI PLANT of UBE KOSAN Industrical Company in Osaka Bay. It is seen that the consplcuous density stratification is formed near the intake. Assuming that $T_{1}=27.5{ }^{\circ} \mathrm{C}, T_{2}=24.3^{\circ} \mathrm{C}$ and $B=3.6 \mathrm{~m}$ from the observed deta, calculation gives $\lambda=0$. Therefore, water temperature of cooling water results in the assumed lower layer temperature, $24.3{ }^{\circ} \mathrm{C}$, which colncldes with the average temperature measured at the pumping pit. 


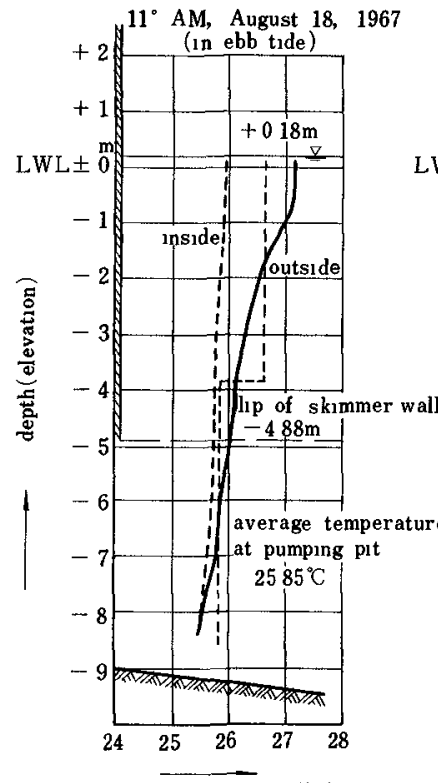

water temperature $\left({ }^{\circ} \mathrm{C}\right)$

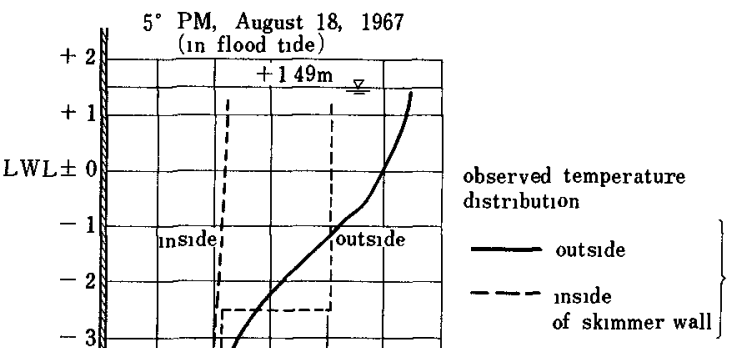

assumed temperature distribution outside of skımmer wall

Fig. 6. Observed water temperature distribution at bottom water intuke for SHIN-SHIMIZU Thermal Power Station.

Studies are further continued to make clear the characteristics of selective withdrawal in the field of continuous density distribution which is generally more actual condition in sea basin. 


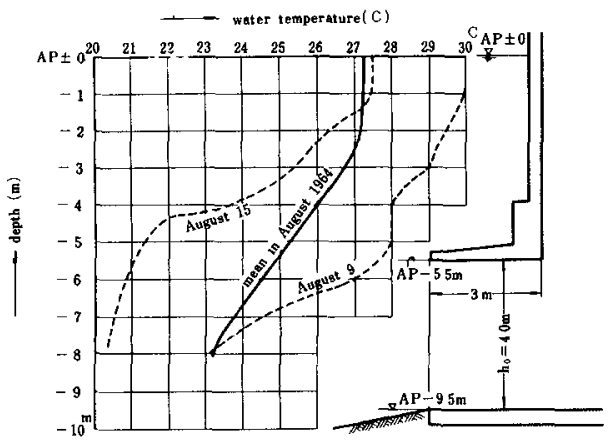

Intake discharge $1467 \mathrm{~m}^{2} / \mathrm{sec}$, average temperature of cooling water in August $236 \mathrm{C}$

F1g. 7 An example of water temperature distribution observed in front of bottom water intake for ICHIHARA Thermal Power Station.

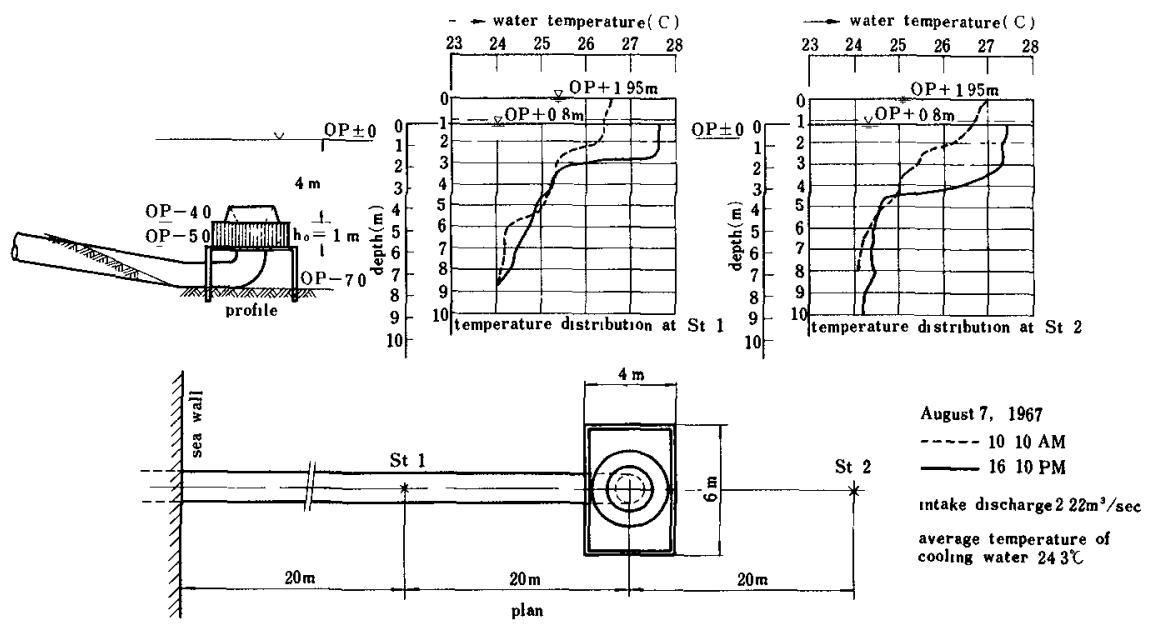

F1g. 8. Water temperature distribution observed at vertical type inlet of intake pipe for SAKAI PLANT of UBE KOSAN INDUSTRIAL COMPANY. 


\section{ACKNOWLEDGEMENT}

The author wishes to express his gratıtude to Dr A. Wada for his advices and to Mr. T. Fujlmoto for his assistance in performing all experiments.

\section{REFERENCE}

S. Senshu and A. Wada "Study on bottom water intake for condenser cooling system of power stations", Proceedings of the loth Conference on Coastal Engineering, 1966 (Tokyo). 